\title{
Wnt/ $\beta$-Catenin Signaling Exacerbates Keloid Cell Proliferation by Regulating Telomerase
}

\author{
Dongmei Yu Yong Shang Jian Yuan Shuang Ding Sai Luo Lijun Hao \\ Plastic and Cosmetic Center, The First Affiliated Hospital of Harbin Medical University, Harbin, China
}

\section{Key Words}

Wnt $\bullet \beta$-catenin $\cdot$ Telomerase $\cdot$ Keloid $•$ Cell proliferation $\bullet$ Apoptosis

\begin{abstract}
Objectives: Our goal was to investigate the relationship between keloid and telomerase as well as clarifying the influence of $\mathrm{Wnt} / \beta$-catenin signaling on keloid cell proliferation. Methods: Tissues from 18 keloid patients were collected for further study. Keloid progenitor cells (KPC) and skin progenitor cells (SKP) were both included in this study. Lenti-virus transfection was used to divide cells into different groups in which cells were treated with different substances: negative control (NC) group, wnt10a siRNA group, $\beta$-catenin siRNA group and TERT siRNA group. KPC cells were injected into 20 male BALB/C nude mice in order to build tumor models. Several experiments including immunohistochemistry, western blot and RT-PCR were conducted in order to detect the corresponding protein expressions and relative mRNA levels. MTT assay and flow cytometry were also conducted for assessing cell proliferation and apoptosis status. Results: $\beta$-catenin and telomerase expression levels in keloid tissues were elevated compared to normal tissues (all $P<0.05$ ). KPC cells in keloid exhibited more dynamic telomerase activity than SKP cells $(P<0.05)$. Luciferase activity assay confirmed that $\beta$-catenin could directly interact with telomerase. After wnt10a/ $\beta$-catenin signaling pathway was inhibited, the proliferation of KPC cells was significantly suppressed and the apoptosis rate was remarkably increased (all $P<0.05$ ). Results from tumor models also validated that wnt10a/ $\beta$-catenin signaling pathway influenced the activity and length of telomerase. Conclusions: Wnt/ $\beta$-catenin signaling pathway is able to exacerbate keloid cell proliferation and inhibit the apoptosis of keloid cells through its interaction with telomerase.
\end{abstract}

\section{Introduction}

Keloid which is characterized by exaggerated response to injury and formation of excessive scar tissues are defined as dermis benign tumors resulted from dysregulated wound healing processes [1]. Many factors contribute to keloids such as race, wound infection and genetic predisposition [2]. African, Asian and Hispanic descents are much 


\section{Cellular Physiology Cell Physiol Biochem 2016;39:2001-2013

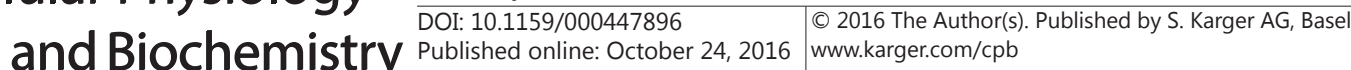 \\ Yu et al.: Role of Wnt/ß-Catenin in Telomerase Regulation for Keloid}

more susceptible to keloids compared with individuals from other ethnicities [3, 4]. Keloids usually occur in head, neck and other parts of the body and a high incidence of relapse is observed in patients with keloids [5]. Keloids not only affect one's appearance but also impair skin functions and other parts of the body may be affected to some degree. As a result of this, this disease imposes significant psychological and physical burdens on patients who suffer from this disease. However, most treatments for managing keloids have very limited effectiveness and it is still challenging to cure this disease. Conventional approaches in conjunction with radiotherapy or corticosteroids have been developed to manage patients with keloid [6]. Several studies have concluded that epithelial-to-mesenchymal transition (EMT) plays a vital role in keloid or hypertrophic scar [7, 8]. Moreover, EMT is likely to be induced by transforming growth factor- $\beta$, other pro-inflammatory cytokines and wingless proteins (Wnt) [9]. Compared with other chronic diseases, keloid pathogenesis is not fully understood and no animal models have been established for investigating how keloids are formed [10]. Therefore, it is worthwhile to further explore the molecular mechanisms of keloids which may provide additional information for the formation of keloids.

Wnt signaling pathway is a complex signaling pathway that is related to cell development. The entire pathway network consists of the independent $\beta$-catenin pathway and the dependent $\beta$-catenin pathway [11]. Abnormal activation of Wnt is closely related to the development of cardiovascular disease, hepatic fibrosis and cancer [12, 13]. Wnt/ $\beta$ catenin signaling pathway which is considered to be the most representative example of Wnt signaling, plays critical roles in diversified cellular functions including cell proliferation, differentiation, migration and apoptosis [14]. Significance of this pathway can be exemplified by the evidence that both over-expression and under-expression of target genes contained in this pathway result in various diseases [15]. Wnt/ $\beta$-catenin signaling pathway should be appropriately regulated in order to provide cells with their normal functions. It is acknowledged that $\beta$-catenin levels are minimized by several destruction complex including Axin, APCGSK3 $\beta$ and casein kinase 1 (CK1) on condition that Wnt is not provoked. As for the nucleus, TCFs block the activation of target genes with the assistance of transcriptional repressors $[16,17]$. The accumulated $\beta$-catenin then combines with the LEF/TCF family transcription factor, converts them from repressors to activators and thus triggers gene transcription starting from the downstream [18]. As suggested by a study on tumor behavior, tumor cell metastasis was achieved through EMT whose process was driven by $\mathrm{Wnt} / \beta$ catenin signaling pathway [19].

The telomerase complex contains two components: TERT, an enzymatic subunit and another RNA compoent which is called Terc. The telomerase controls the telomere length and affects stem cells, aging process and cancer development [20]. More importantly, telomeres contain specific genomic structures that are indispensable parts of genome stability [21]. Chromosome stability of telomere is lost and the length of human telomere starts to downsize after several times of cell cycles in the case of cell proliferation and aging [22]. Telomere/ telomerase interplay has been indicated to be an important mechanism which is involved in cellular replicative potential and genomic stability. Besides that, telomere/telomerase dysfunction has significant impact on carcinogenesis [23]. The regulation of telomerase by wnt/ $\beta$-Catenin Signaling pathway has been studied in both stem cells and cancer cells [24]. Mutations in $\beta$-catenin contributed to an increased Tert expression in cancer and resulted in telomeres stabilization which is a significant tumorigenesis marker. The provoking of telomerase in keloid contributes to the maintenance of telomere length. However, telomerase activity is inhibited in developed keloid [24]. Wnt/ $\beta$-catenin signaling pathway may activate related gene expressions and thus influences the development of keloid [25]. So far, researches which focus on the mechanism of telomeres and Wnt/ $\beta$-Catenin Signaling pathway in keloids are still scarce.

This research is designed to employ models in vitro and in vivo for the purpose of investigating Wnt/ $\beta$-catenin signaling and telomerase activity in keloids. We hypothesized that Wnt/ $\beta$-catenin signaling exacerbated cell proliferation and apoptosis by regulating telomerase and this mechanism may explain the formation of keloids. 


\section{Cellular Physiology Cell Physiol Biochem 2016;39:2001-2013 \begin{tabular}{l|l|l} 
and Biochemistry 10.1159/000447896 & $\begin{array}{l}\text { C) 2016 The Author(s). Published by S. Karger AG, Basel } \\
\text { www.karger.com/cpb }\end{array}$ \\
\hline Published online: October 24, 2016
\end{tabular} \\ Yu et al.: Role of Wnt/ß-Catenin in Telomerase Regulation for Keloid}

\section{Materials and Methods}

\section{Ethics statement}

Collection of human tissues was authorized by the Ethics Committee of The First Affiliated Hospital of Harbin Medical University based on the Helsinki Declaration. Informed consent was specifically required for each patient. All mice experiments were complied with the Guidance for Care and Usage of Laboratory Animals and were accepted by the National Cancer Institute Animal Care and use committee.

\section{Patient samples}

Keloid specimens ( $\mathrm{n}=18)$, including 12 males and 6 females, were collected from The First Affiliated Hospital of Harbin Medical University between May 2014 and Dec 2014. Both keloid tissues and related peripheral normal skin tissues were collected from patients, which were used to compare molecule expressions and isolate stem cells from tissues.

\section{Immunohistochemistry}

Immunohistochemical analysis of $\beta$-catenin in tissue samples was carried out by using the two-step EnVision method as described previously [26]. In brief, after being frozen and sliced, samples were applied with Rabbit polyclonal anti- $\beta$-catenin antibody (dilution 1:100, Zhongshan Biology Company, Beijing) as the primary antibody, and then incubated with horseradish peroxidase-conjugated (HRP-conjugated) goat antirabbit IgG (1:800, Zhongshan Biology Company, Beijing) as the secondary antibody. After being visualized with diaminobenzidine (DAB, Sigma, USA), samples were hydrated, washed and analysis in microscopy.

\section{Cell isolation and culture}

Keloid progenitor cells (KPC) and skin progenitor cells (SKP) were separated from 5 keloid tissues and 5 matched normal skin tissues, respectively as previously described [27]. In brief, aseptical tissues were cut into small pieces and treated with dispase in order to generate scattered cells which were filtered with a $70-\mu \mathrm{m}$ strainer. Cells were cultured in Dulbecco modified Eagle medium (Gibco, Carlsbad, CA) with 10\% fetal bovine serum (Gibco, Carlsbad, CA) at $37^{\circ} \mathrm{C}$ in an incubator with $5 \% \mathrm{CO}_{2}$.

\section{Lenti-virus transduction and transfection}

Four groups of fragments, separately containing NC, wnt10a siRNA, $\beta$-catenin siRNA and TERT siRNA were cloned into the pCDH vector. Then $\mathrm{PCDH}$ vectors with other packaging plasmids were co-transfected into cells using Lipofectamine LTX kit (Invitrogen, CA) and the viral particles therein were collected 48h after transfection.

KPC cells were infected with five groups of recombinant lentivirus and $8 \mathrm{ug} / \mathrm{ml}$ polybrene: control group (cells without any transfection), NC group (cells transfected with negative vector), wnt10a siRNA group (cells transfected with wnt10a siRNA), $\beta$-catenin siRNA group (cells transfected with $\beta$-catenin siRNA) and TERT siRNA group (cells transfected with TERT siRNA).

\section{Transplantation in vivo}

A total of 20 male BALB/c nude mice (Laboratory Animal Center of The First Affiliated Hospital of Harbin Medical University) with an average age of 4 weeks and weight of 16-18g were obtained for establishing tumor growth models. Briefly, KPC cells were subcutaneously injected into the neck of mice $\left(1 \times 10^{6}\right.$ cells each mice). Seven days after tumor volumes were quantified, tumor sites of mice in the four groups ( 5 mice per group) were transfected with four types of lenti-virus expressing vectors (control, wnt10a siRNA, $\beta$-catenin siRNA and TERT siRNA) through direct injection $\left(2 \times 10^{7}\right.$ units each time, twice a week) for a period of 14 days. Tumor volume of mice in each group was calculated 28 days after the injection using the following formula: volume $=\left(\mathrm{A} \times \mathrm{B}^{2}\right) / 2$, where $\mathrm{A}=$ the biggest diameter and $\mathrm{B}=$ the smallest diameters.

Telomerase mutant sable cells and luciferase promoter-reporter transient transfection experiments

Mutated binding sites (four TCF-4 binding elements, TBE1-4) in the telomerase-promoter were established by using the system of Gene Tailor Site-Directed Mutagenesis (Invitrogen, USA) and the corresponding mutated sequences were showed in Table 1 . Then wild type and mutated promoter of telomerase were cloned into the downstream of the psiCHECK-2 luciferase vector (Promega, USA), which was named as wt promoter and mut TBE1-4 promoter, respectively. 


\section{Cellular Physiology Cell Physiol Biochem 2016;39:2001-2013 \begin{tabular}{l|l|l} 
and Biochemistry & DOI: 10.1159/000447896 & $\begin{array}{l}\text { C) 2016 The Author(s). Published by S. Karger AG, Basel } \\
\text { www.karger.com/cpb }\end{array}$ \\
\hline
\end{tabular}}

Yu et al.: Role of Wnt/ß-Catenin in Telomerase Regulation for Keloid

KPC cells were maintained in plates with 48 wells and were transfected with three groups of substances: one group was transfected with the combination of $160 \mathrm{ng}$ pcl-neo- $\beta$-catenin-D45 encoding expression plasmid, 40ng pCMV-Remnilla and $120 \mathrm{ng}$ wt promoters, while wt promoters in the other two groups were either replaced by mut TBE1-4 promoter or negative control plasmid. The transfected cells were inspected by the Dual-Luciferase Reporter Assay System (Promega) 48h after the transfection.

\section{Chromatin immunoprecipitation (chip)}

ChIP assay was achieved with ChIP-IT kits (Active Motif). In brief, chromatin of KPC cells was cut into approximately 400 bp by ultra-sound sonification (20-30 sec pause for five times, HTU SONI130), and then immunoprecipitated with antibodies included specific $\beta$-catenin antibodies (Sigma) for human cells, as well as mice IgG (Active Motif) as isotype controls. The reverse-crosslinked chromatin precipitates were analysis with real-time PCR (RT-PCR) with $10 \%$ precipitates as template and $400 \mathrm{nM}$ of each primer spanning the region of human Tert $-2000 /-1000 /+1000 /+2000$ (relevant primers were listed in Table 2). Water and input chromatin were listed as negative and positive control, respectively.

\section{Cell proliferation and apoptosis assay}

MTT assay was carried out to inspect the status of cell proliferation. A total of $3 \times 10^{3}$ cells were cultured in 96-well plates and incubated for five different periods of time $(24 \mathrm{~h}, 48 \mathrm{~h}, 72 \mathrm{~h}$, $96 \mathrm{~h}$ and $120 \mathrm{~h}$ ) and then cultured cells were stained with $0.5 \mathrm{mg} / \mathrm{ml}$ Methylthiazolyldiphenyltetrazolium bromide (MTT) for $4 \mathrm{~h}$. Subsequently, we discarded the supernatant and added 200ul dimethylsulfoxide for the purpose of dissolving precipitate. Samples were measured at $490 \mathrm{~nm}$ by an ELISA reader. Apoptosis rates of samples were calculated using flow cytometry after cells were stained with Annexin V-FITC/PI Apoptosis Detection Kit (BD Biosciences).

Telomerase activity and telomere length assay

Telomerase activity was quantified using the telomeric repeat amplification protocol
Table 1. Sequences of telomerase promoter in luciferase promoter-reporter transient transfection experiments. WT: wild type; Mut: mutation

\begin{tabular}{lll}
\hline Gene & \multicolumn{2}{l}{ WT } \\
\hline \multirow{2}{*}{ TBE3 } & WT & 5'-ATTATTTCAAAACAAAGGTTTACATAAA-3' \\
& Mut & 5'-ATTATTTCAACGCAGAGGTTTACAGAAA-3' \\
\multirow{2}{*}{ TBE4 } & WT & 5'-GAGTTACCCTCCTTTGATATTTTCTGTA-3' \\
& Mut & 5'-GAGTTACCCTCCTGTGCGATTTTCTGTA-3' \\
\hline
\end{tabular}

Table 2. Primer sequences of RT-PCR in ChIP assay. TSS: transcriptional start site

\begin{tabular}{lll}
\hline Gene & \multicolumn{2}{c}{ Primer sequence } \\
\hline \multirow{2}{*}{ Tert -2000 } & Sense & 5'-TGCAAGATGAAGCAAACAGAG-3' \\
& Antisense & 5'-TCTCAGTACCCCTCCCTCAC-3' \\
\multirow{2}{*}{ Tert-1000 } & Sense & 5'-CCCTATTTCCCAGAGATTCAAA-3' \\
& Antisense & 5'-GGGGCATATGTAATGACACGA-3' \\
\multirow{2}{*}{ Tert TSS } & Sense & 5'-ACTTTGGTTGCCCAATGC-3' \\
& Antisense & 5'-AAGGAAAGGTCGGCAGGT-3' \\
\multirow{2}{*}{ Tert +1000 } & Sense & 5'-CAGGAACTGATGTGGAAGATGA-3' \\
& Antisense & 5'-AGACCAGCCATGCTCACC-3' \\
\multirow{2}{*}{ Tert +2000 } & Sense & 5'-TGGATAGGAGTTCTGGCACA-3' \\
& Antisense & 5'-CGGGCCCTTACATTAGCTCT-3' \\
\hline
\end{tabular}

Table 3. Primer sequences of GADPH, wnt10a, $\beta$-catenin and telomerase for implemention of RT-PCR. GAPDH: glyceraldehyde phosphate dehydrogenase, RTPCR: real time-polymerase chain reaction

\begin{tabular}{lll}
\hline Gene & & Primer sequence \\
\hline \multirow{2}{*}{ GAPDH } & Sense & 5'-TGGTATCGTGGAAGGACTCAT-3' \\
& Antisense & 5'-GTGGGTGTCGCTGTTGAAGTC-3' \\
\multirow{2}{*}{ Wnt10a } & Sense & 5'-GGGCTCAGGTTCCTACTTCC-3' \\
& Antisense & 5'-AAGGAGAAGCCTCCCAAGAG-3' \\
\multirow{2}{*}{$\beta$-catenin } & Sense & 5'-AGCTGACCAGCTCTCTCTTCA-3' \\
& antisense & 5'-CCAATATCAAGTCCAAGATCAGC-3' \\
\multirow{2}{*}{ Telomerase } & Sense & 5'-CACGCGAAACCTTCCTC-3' \\
& antisense & 5'-ACCACTGTCTTCCGCAAGTT-3' \\
\hline
\end{tabular}

(TRAP) in conjunction with the fluorescent telomerase repeat amplification kit (Roche). DNeasy blood and tissue kit (Qiagen) were implemented for telomere length assay and DNA was isolated from cells. Then non-radioactive Tell-TAGGG telomere length assay was conducted to measure telomer length by hybridizing telomere into probes labeled with digoxigenin and telomere length was quantified by photometric enzyme immunoassay.

\section{Isolated rna and the implementation of rt-pcr}

We used the TRIzol reagent (Invitrogen) for RNA extraction and the ReverTra Ace qPCR RT Kit (Toyobo, Japan) was manipulated in order to reversely transcribe total RNA into cDNA. Furthermore, the real time-PCR (RT-PCR) was carried out by using the THUNDERBIRD SYBR® qPCR Mix (Toyobo, Japan) which was assisted with the CFX96 Touch Real-Time PCR Detection System (Bio-Rad). Relevant primers were presented in 


\section{Cellular Physiology Cell Physiol Biochem 2016;39:2001-2013 \begin{tabular}{l|l|l|} 
DOI: 10.1159/000447896 & $\begin{array}{l}\text { (c) 2016 The Author(s). Published by S. Karger AG, Basel } \\
\text { www.karger.com/cpb }\end{array}$
\end{tabular}}

Yu et al.: Role of Wnt/ß-Catenin in Telomerase Regulation for Keloid

Table 3. Target gene expressions were normalized to those of the control gene (glyceraldehyde-3-phosphate dehydrogenase, GAPDH) and we performed the corresponding calculations using the approach of $2^{-\triangle \triangle C T}$.

\section{Western blot}

Firstly, we used the radio immunoprecipitation assay (RIPA) buffer to harvest and lyse tissues and cells obtained from samples. Then, total proteins were separated and quantified using the Bradford method [28]. Subsequently, the corresponding proteins were denatured in boiled water and further transferred onto Polyvinylidene Fluoride (PVDF) membranes after the implementation of sodium dodecyl sulfatepolyacrylamide gel electrophoresis (SDS-PAGE). After that, membranes were blocked for one hour in Tris Buffered Saline Tween (TBST) in which 5\% skim milk was added. Once these steps were completed, membranes were treated with primary antibodies against wnt10a, $\beta$-catenin and telomerase (1:800 dilution, Zhongshan Biology Company, Beijing) overnight at the temperature of $4^{\circ} \mathrm{C}$. Following a complete wash, membranes were incubated with secondary antibodies (horseradish peroxidase-conjugated goat anti-goat, 1:2000 dilutions, Zhongshan Biology Company, Beijing). Finally, samples in which reduced GAPDH was set as the endogenous control was inspected by using enhanced chemiluminescence and the corresponding data were analyzed using the Lab Works4.5 software (Mitov Software).

\section{Statistical analysis}

All statistical procedures were implemented using the SPSS 18.0 software (Chicago, Illinois, USA). The empirical student's t-test as well as the one way analysis of variance (ANOVA) were used to infer whether there is significant difference in these data among different groups and statistical significance was concluded if $P$-value $<0.05$.

\section{Results}

Active wnt10a, $\beta$-catenin and telomerase were expressed in keloid tissues

Results from immunohistochemistry showed that stained Wnt10a was more apparent in the area of stratum granulosum in keloid tissues (Fig. 1A) compared with normal tissues

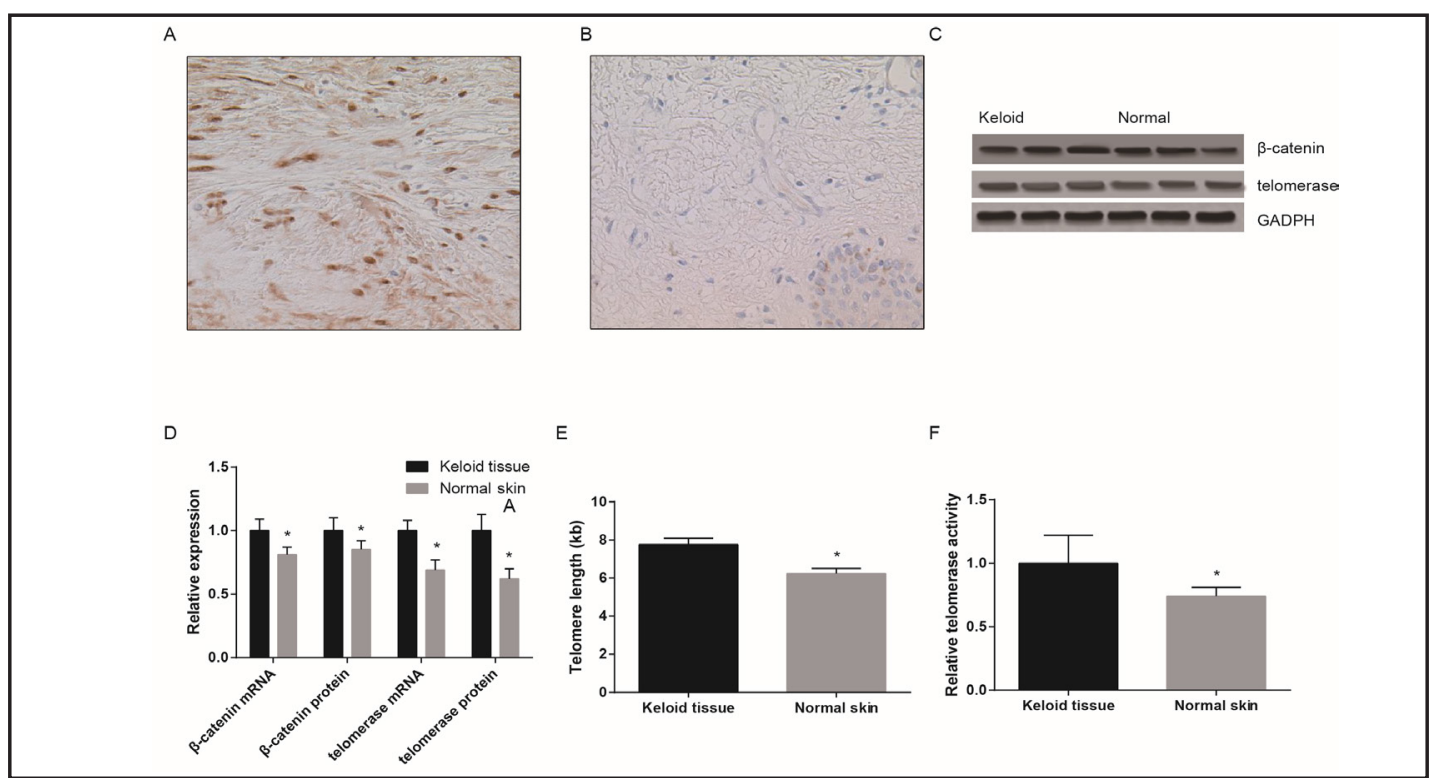

Fig. 1. Expression of wnt10a, $\beta$-catenin and telomerase in keloid tissues and normal skin (mean \pm SD). A-B: Immunohistochemical staining with wnt10a (stained as yellow) in keloid tissues (A) and normal skin (B). C: Western blot analysis of $\beta$-catenin and telomerase in tissues with GAPDH as internal control. D: Quantitative mRNA and protein expressions of $\beta$-catenin and telomerase in keloid tissues and normal skin. E-F: Quantitative data of telomere length (E) and telomerase activity (F) in keloid tissues and normal skin. Data were presented as mean \pm SD for 18 keloid specimens ${ }^{*} P<0.05$ vs. keloid tissues. 
A

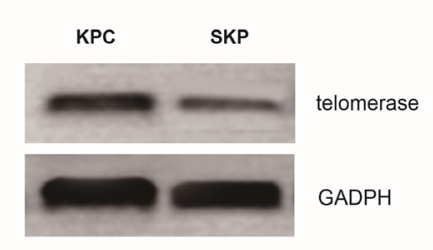

C

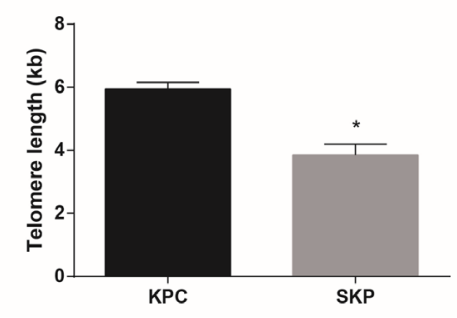

B

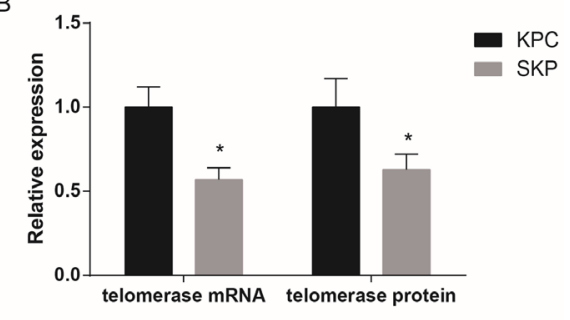

D

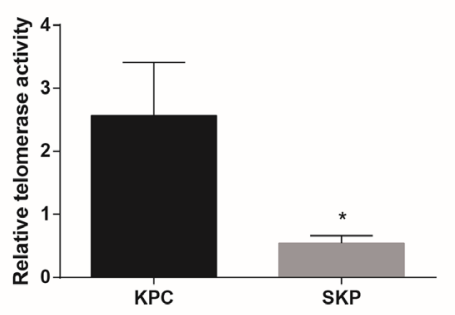

Fig. 2. Expression and activity of telomerase in KPC and SKP cells (mean \pm SD). A: Western blot of telomerase in KPC and SKP cells (internal control = GAPDH). B: Quantified mRNA and protein level of telomerase in KPC and SKP cells. C-D: Quantified data of telomere length (C) and telomerase activity (D) in KPC and SKP cells. KPC: keloid progenitor cells; SKP: skin progenitor cells. Data were presented as mean \pm SD for three independent experiments. ${ }^{*} P<0.05$ vs. KPC group.

(Fig. 1B). Besides that, keloid tissues displayed significantly higher mRNA and protein expressions of $\beta$-catenin and telomerase in comparison to normal tissues, (all $P<0.05$, Fig. $1 \mathrm{C}, \mathrm{D}$ ). In addition, comparative analysis of telomere length and telomerase activity revealed that keloid tissues exhibited relatively larger telomere length and higher telomerase activity than normal skin tissues (all $P<0.05$, Fig. 1E, F).

Kpc cells in keloid tissues exhibited more dynamic telomerase activities

KPC cells were isolated from keloid tissues and SKP cells were collected from normal skin tissues. As shown in Fig. 2A, B, KPC cells exhibited significantly higher mRNA and protein expressions of telomerase than SKP cells (all $P<0.05$ ). In subsequent experiments, telomere lengths were examined in cell stably transduced for 30 days, significantly longer telomere length and more dynamic telomerase activities were also identified in KPC cells compared with SKP cells (all $P<0.05$, Fig. 2C, D).

$\beta$-catenin bound with the sites in the 3' promoter of telomerase

A possible link between $\beta$-catenin and telomerase was facilitated by the binding site of TCF-4 binding elements (TBEs). Telomerase gene was analyzed and four TBEs were identified in the 3' promoter of telomerase (Fig. 3A). Luciferase activity assay confirmed a direct interaction between $\beta$-catenin and telomerase with evidence that co-transfection of $\beta$-catenin and 3' promoter of telomerase had significantly higher luciferase activity than the NC group in which $3^{\prime}$ promoter of telomerase was replaced by the plasmid vector $(P<$ 0.05 , Fig. $3 B$ ). Moreover, the mutation of TBEs can remarkably down-regulated the luciferase activity $(P<0.05$, Fig. 3B).

Then we further validated the results with ChIP assay. When compared with Tert siRNA group, significantly higher level of chromatin precipitates was identified in WT group at transcriptional start site (TSS) $(P<0.05)$, whereas no significant difference was observed between two groups at $-2000 /-1000 /+1000 /+2000$ sites $(P<0.05$, Fig. $3 C)$ 


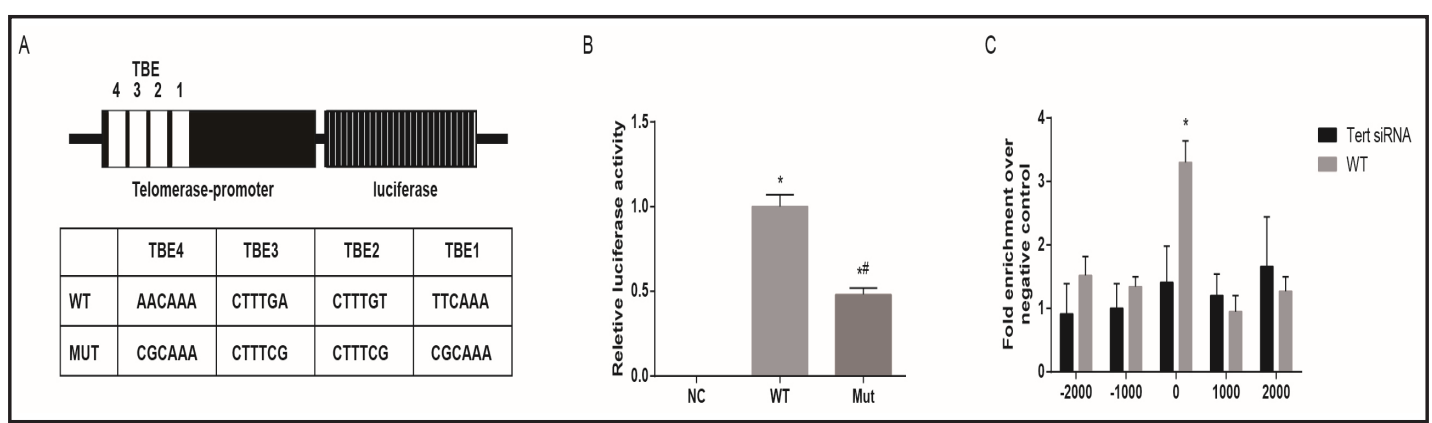

Fig. 3. $\beta$-catenin interacted with TCF-4 binding elements (TBEs) in telomerase promoter and confers transcriptional activation. A: Sequences of telomerase promoter and promoter with mutation in TBEs. B: Relative luciferase activity in groups of NC, WT and Mut. NC: negative control vector; WT: wild type of telomerase promoter; Mut: telomerase promoter with mutation in TBEs. ${ }^{*} P<0.05$ vs. NC group, ${ }^{\#} P<0.05$ vs. WT group. C: ChIP analysis between $\beta$-catenin and Tert. ${ }^{*} P<0.05$ vs. Tert siRNA group. Data were presented as mean \pm SD for three independent experiments.

Fig. 4. Effects of wnt10a siRNA, $\beta$-catenin siRNA and telomerase siRNA on proliferation of KPC cells by means of MTT assay. Data were presented as mean \pm SD for three independent experiments.

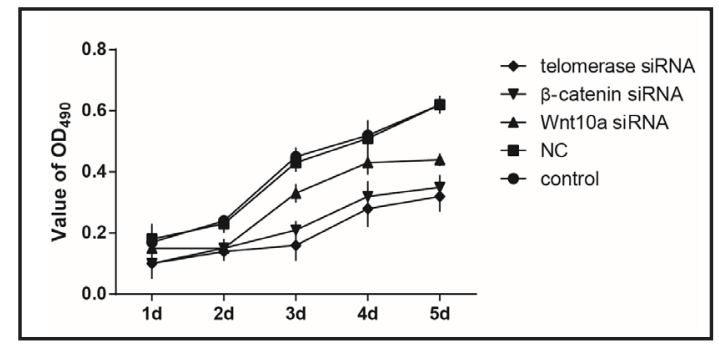

Effects of wnt/ $\beta$-catenin on proliferation and apoptosis of kpc cells

MTT assays revealed that significant differences in KPC cell proliferation and apoptosis among different groups of transfection were identified since day 3 of the cell culture process. The proliferative capability of KPC cells transfected with wnt10a siRNA, $\beta$-catenin siRNA and telomerase RNA were notably inhibited in comparison to those of cells transfected with the negative control. Generally, silencing of wnt10a can significantly suppress the proliferation rate compared with the control and NC group, while silencing of both $\beta$-catenin and telomerase can further down-regulate the proliferation rate with a greater degree than single silencing of wnt10a $(P<0.05)$. There appeared to be insignificant difference in the proliferation rate between the $\beta$-catenin siRNA and TERT siRNA group $(P>0.05$, Fig. 4).

Results from flow cytometry illustrated that no obvious difference in cell apoptosis status was observed between the control and NC group. Similarly, no substantial difference in cell apoptosis status was observed between the wnt10a siRNA and $\beta$-catenin siRNA group (all $P>0.05$, Fig. 5). Transfection of wnt10a siRNA and $\beta$-catenin siRNA can remarkably stimulate the apoptosis of KPC cells in comparison to the control and NC group, while TERT siRNA group exhibited the lowest apoptosis rate compared with the control, NC, wnt10a siRNA and $\beta$-catenin siRNA group (all $P<0.05$, Fig. 5).

\section{Effects of sirna on wnt10a, $\beta$-catenin and telomerase expressions}

No substantial difference in mRNA and protein expressions of wnt10a, $\beta$-catenin and telomerase was detected between the control and NC group (all $P>0.05$ ). Silencing of wnt10a can significantly decrease mRNA and protein expressions of wnt10a and telomerase as well as $\beta$-catenin protein, while silencing of $\beta$-catenin can remarkably decrease mRNA and protein expression of $\beta$-catenin and telomerase $(P<0.05)$. Moreover, silencing of telomerase is able to down-regulate mRNA and protein expressions of telomerase (all $P<0.05$, Fig. 6). 
A

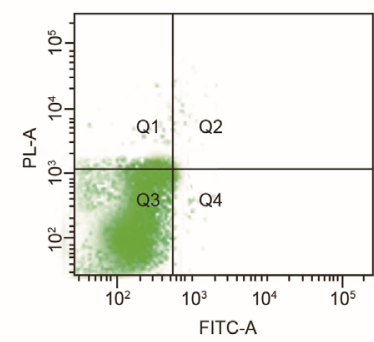

D

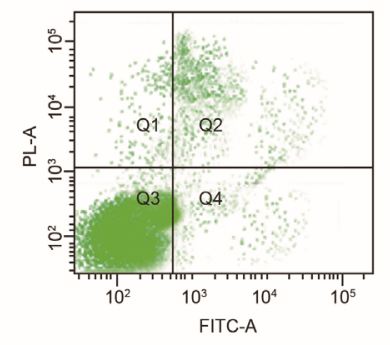

B

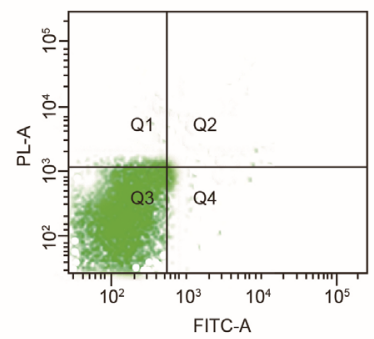

E

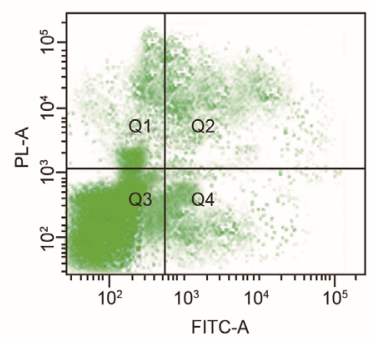

C

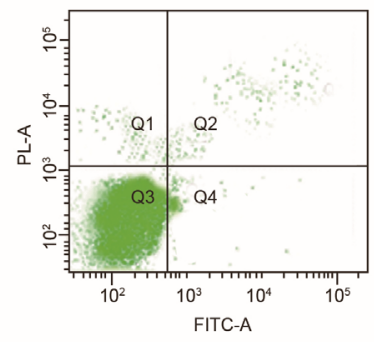

$\mathrm{F}$

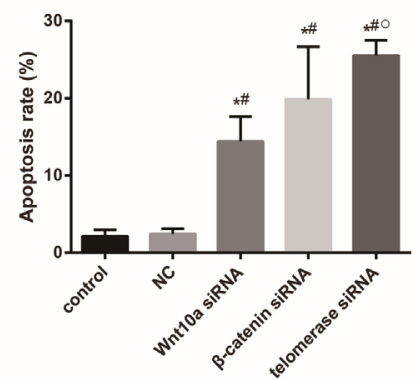

Fig. 5. Apoptosis rate of cells estimated by flow cytometry. A-E: Distribution of apoptotic cells in the control (A), NC (B), wnt10a siRNA (C), $\beta$-catenin siRNA (D) and telomerase siRNA (E) group. F: Relative apoptosis rate of cells in each group. Data were presented as mean \pm SD for three independent experiments. ${ }^{*} P<0.05$ vs. control group, ${ }^{\#} P<0.05$ vs. NC group, ${ }^{\circ} P<0.05$ vs. wnt10a siRNA group.

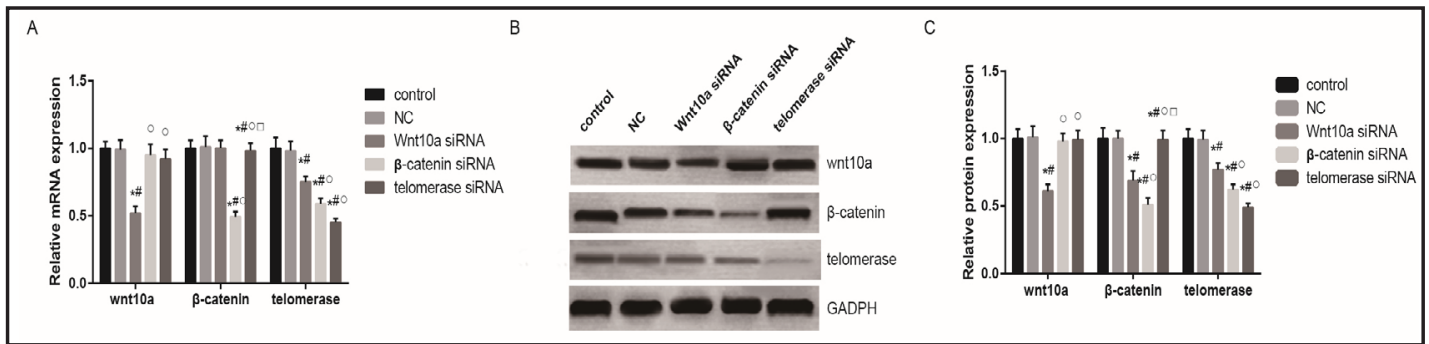

Fig. 6. Expression of wnt10a, $\beta$-catenin and telomerase in KPC cells after transfection. A: Quantitative mRNA levels of wnt10a, $\beta$-catenin and telomerase in KPC cells among different groups (i.e. control, NC, wnt10a siRNA, $\beta$-catenin siRNA and telomerase siRNA). B: Western blot analysis of wnt10a, $\beta$-catenin and telomerase in KPC cells with GAPDH as internal control. C: Quantified protein level of wnt10a, $\beta$-catenin and telomerase in KPC cells. Data were presented as mean \pm SD for three independent experiments. ${ }^{*} P<0.05$ vs. control group, ${ }^{\#} P<0.05$ vs. NC group, ${ }^{\circ} P<0.05$ vs. wnt10a siRNA group, ${ }^{\square} P<0.05$ vs. $\beta$-catenin siRNA group.

\section{Sirna of wnt10a, $\beta$-catenin and telomerase inhibited telomerase activity in kpc cells}

Transfection of the negative control vector did not significantly affect telomere length or telomerase activity in KPC cells (all $P>0.05$ ). Cells in the wnt10a siRNA group exhibited shorter telomere compared with the control and $\mathrm{NC}$ group, while silencing of $\beta$-catenin can further restrict telomere length. Interestingly, silencing of telomerase contributed to the shortest telomere length in comparison to the control, $\mathrm{NC}$, wnt10a siRNA and $\beta$-catenin siRNA group (all $P<0.05$, Fig. 7A). In addition, transfection of wnt10a siRNA, $\beta$-catenin siRNA and TERT siRNA had similar effects on suppressing the activity of telomerase in KPC cells (all $P<0.05$, Fig. 7B).

\section{Results from animal models}

To further investigate the effects of wnt10a siRNA, $\beta$-catenin siRNA and TERT siRNA on tumor growth, a human keloid-bearing mice model in vivo was built by injecting KPC cells 
A

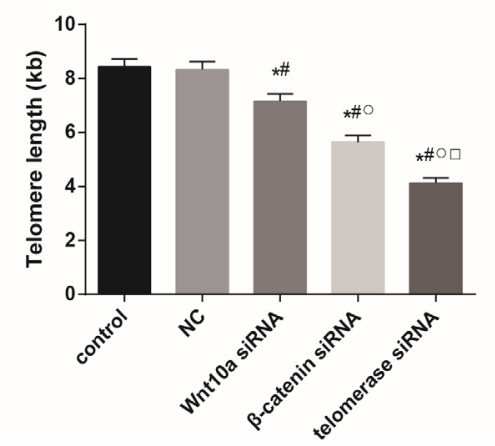

B

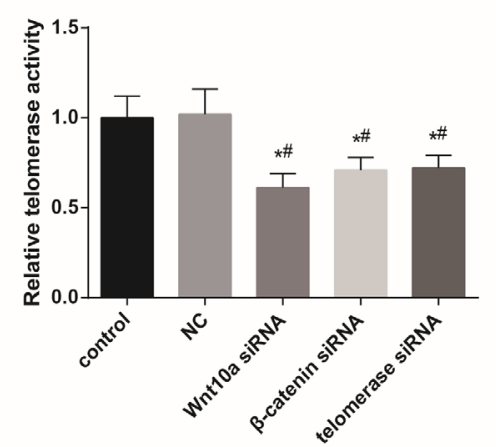

Fig. 7. Quantitative data of telomere length (A) and telomerase activity (B) in KPC cells among different groups (i.e. control, NC, wnt10a siRNA, $\beta$-catenin siRNA and telomerase siRNA). Data were presented as mean \pm SD for three independent experiments. ${ }^{*} P<0.05$ vs. control group, ${ }^{\#} P<0.05$ vs. NC group, ${ }^{\circ} P<0.05$ vs. wnt10a siRNA group, ${ }^{\square} P<0.05$ vs. $\beta$-catenin siRNA group.

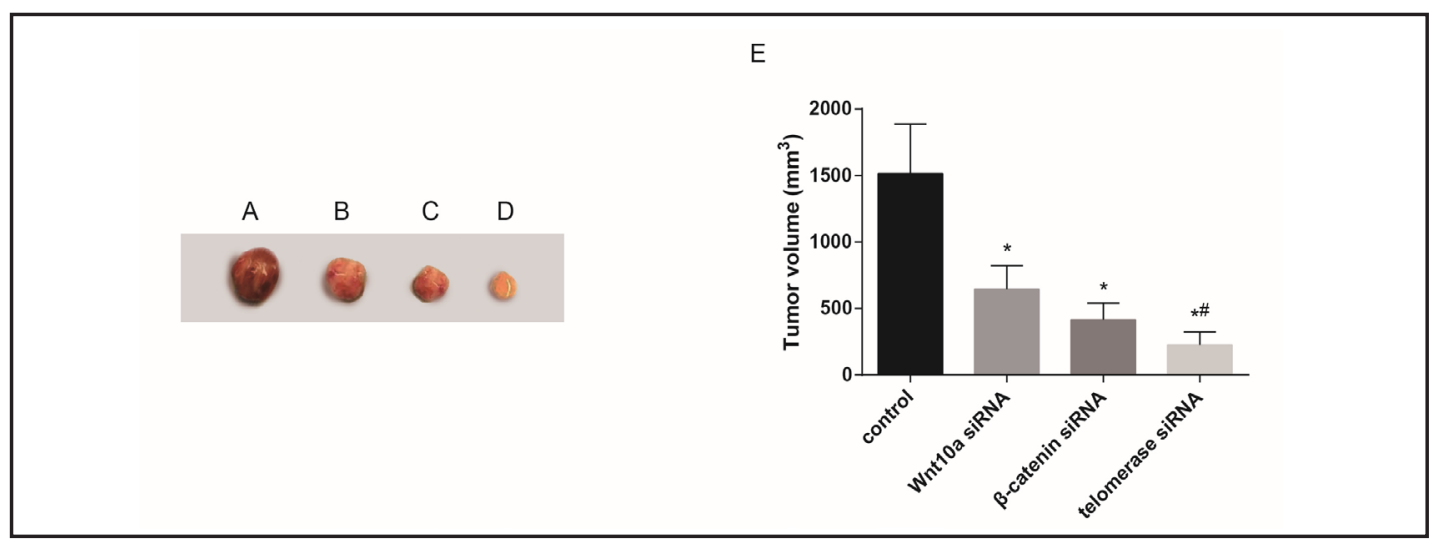

Fig. 8. Effects of wnt10a siRNA, $\beta$-catenin siRNA and telomerase siRNA on tumor growth in vivo. A-D Size of transplantations generated from KPC cells in the control (A), wnt10a siRNA (B), $\beta$-catenin siRNA (C) and telomerase siRNA (D) group. E: Quantitative data of tumor volumes in mice models after transplantation of KPC cells. Data were presented as mean \pm SD for three independent experiments. Data were presented as mean \pm SD for five independent experiments. ${ }^{*} P<0.05$ vs. control group, ${ }^{\#} P<0.05$ vs. wnt10a siRNA group.

into mice and hence transplanted tumors were formed. After tumors of mice in each group were separated, we observed that tumor volumes of mice in the wnt10a siRNA, $\beta$-catenin siRNA and TERT siRNA group were much smaller than in relation to the control group, while the TERT siRNA group had significantly smaller tumors compared with the wnt10a siRNA group (all $P<0.05$, Fig. 8).

Similar to the results in vitro, transfection of wnt10 siRNA can significantly downregulate both mRNA and protein expressions of wnt10a and telomerase as well as $\beta$-catenin mRNA in modeled mice, while silencing of $\beta$-catenin can remarkably decrease both mRNA and protein expressions of $\beta$-catenin and telomerase. Furthermore, silencing of telomerase is able to down-regulate both mRNA and protein expressions of telomerase (all $P<0.05$, Fig. 9).

In addition, the wnt10a siRNA group exhibited smaller telomere length and less dynamic telomerase activity compared with the control group, while silencing of $\beta$-catenin can further restrict telomere length and telomerase activity compared with silencing of wnt10a. Of note, TERT siRNA group had the lowest telomere length and telomerase activity compared with the control, wnt10a siRNA and $\beta$-catenin siRNA group (all $P<0.05$, Fig. 10).

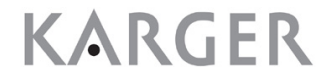




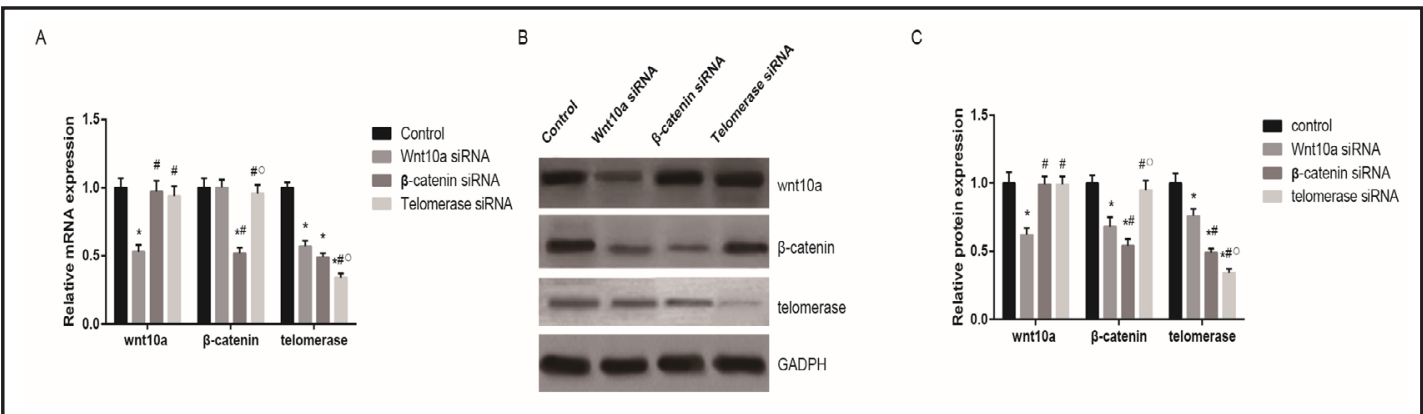

Fig. 9. Expression of wnt10a, $\beta$-catenin and telomerase in nude mice models with KPC cells transplantation. A-D: Immunohistochemical staining with wnt10a (stained as yellow) in tissue samples from control group (A), wnt10a siRNA group (B), $\beta$-catenin siRNA (C) and telomerase siRNA (D). E: Quantitative mRNA levels of wnt10a, $\beta$-catenin and telomerase in model mice within four groups (i.e. control, wnt10a siRNA, $\beta$-catenin siRNA and telomerase siRNA). F: Western blot analysis of wnt10a, $\beta$-catenin and telomerase in model mice with GAPDH as internal control. G: Quantified protein levels of wnt10a, $\beta$-catenin and telomerase in model mice. Data were presented as mean \pm SD for five independent experiments. ${ }^{*} P<0.05$ vs. control group, ${ }^{\#} P<0.05$ vs. wnt10a siRNA group, ${ }^{\circ} P<0.05$ vs. $\beta$-catenin siRNA group.
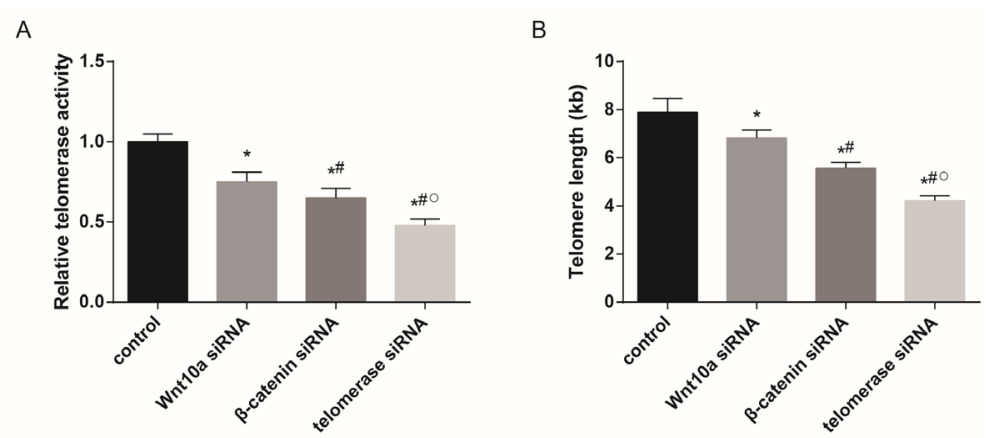

Fig. 10. Quantitative data of telomere length. (A) and telomerase activity (B) in model mice within four groups (i.e. control, wnt10a siRNA, $\beta$-catenin siRNA and telomerase siRNA). Data were presented as mean \pm SD for five independent experiments. ${ }^{*} P<0.05$ vs. control group, ${ }^{\#} P<0.05$ vs. NC group, ${ }^{\circ} P<0.05$ vs. wnt10a siRNA group.

\section{Discussion}

The current study has suggested that knocking-down of Wnt10a/ $\beta$-catenin signaling significantly blocked proliferation and facilitated apoptosis of KPC cells through its suppressive effect on both telomerase expression and telomere length. Another study conducted by Hoffmeyer et al. reported that $\beta$-catenin controlled Klf4 expression by interacting with telomerase in mouse embryonic stem cells [24]. Several studies concluded that telomerase played a key role in regulating cell proliferation which is associated with various disorders (e.g. endometriosis and colorectal cancer) [29-32]. In fact, Wnt/ $\beta$-catenin has been documented to exacerbate cell proliferation by binding with the T-cell factor (TCF)/ lymphoid-enhancing factor (LEF) family and inducing some oncogene expressions including C-myc and cyclin D1(CCND1) [33]. Additionally, Wnt/ $\beta$-catenin inhibited cell apoptosis by closing mitochondrial permeability transition pore (mPTP) for avoiding pro-apoptotic factor release [34]. All in all, cell proliferation and apoptosis are both affected by wnt/ $\beta$-catenin signaling and such a mechanism should be further investigated. Furthermore, Zhang et al. suggested that $\beta$-catenin enhanced telomerase transcription in human cancers by directly targeting TCF4 [35]. Our study provided similar evidence that $\beta$-catenin directly bound with

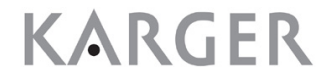


the TCF4 binding elements in the 3' promoter of telomerase in KPC cells. However, Choi et al. argued that telomerase exacerbated epithelial proliferation by transcriptional control of Wnt/ $\beta$-catenin signaling pathway [36]. Similarly, Park et al. also reported that telomerase could directly target Wnt/ $\beta$-catenin signaling genes in mouse gastrointestinal tract [37]. As a result, the activation of Wnt/ $\beta$-catenin and the transcription of telomerase formed an autocrine loop of the signaling pathway.

Another study conducted by Smith et al. observed that inhibitors of the Wnt signaling pathway were reduced in keloid pathogenesis [38]. However, how Wnt/ $\beta$-catenin signaling pathway is influenced by keloid pathogenesis is still unclear mystery. In our study, wnt10a might be responsible for activating the Wnt/ $\beta$-catenin signaling pathway in keloids pathogenesis. Wnt10a is a canonical Wnt ligand that initiates telomerase transcription [39]. There appeared to be some evidence which suggested that the wnt/ $\beta$-catenin signaling pathway is triggered by Wnt5a in keloid pathogenesis [40]. Sato et al. indicated that transforming growth factor (TGF)- $\beta$ stimulated the Wnt/ $\beta$-catenin signaling pathway in hypertrophic scar and keloid tissues via the Smad3 and p38 MAPK pathways [41]. On top of that, Lee et al. demonstrated that the formation and development of keloid was contributed by the mesenchymal transition of dermal microvascular endothelial cells which is caused by wnt3a [42]. Thus, multiple factors might be involved in the activation of Wnt/ $\beta$-catenin which is related to keloid pathogenesis.

Although this study revealed that telomere length was positively correlated with keloid cell proliferation, the effect of changes in telomere length on keloid is still unfolded. For instance, Granick et al. reported that telomere length in the keloid tissues was larger than that in normal tissues during the early stage of keloid formation, while telomerase activity was suppressed in well-developed keloid tissues [43]. Besides that, De Felice et al. demonstrated that reactive oxygen species (ROS) stress contributed to the restriction of telomere length in keloid tissues [44]. All of these controversial results may result from different types of cells used in experiments and varied experimental designs, suggesting that telomerase functions are likely to vary across different types of cells. Apart from that, other pathways are likely to play roles in keloid pathogenesis which is affected by telomerase activity. For instance, Xiao et al. reported that wild type p53 protein can transiently inhibit the telomerase activity of keloid fibroblasts (KFBs) [45].

For summary, this study provided notion that Wnt/ $\beta$-catenin signaling pathway regulated cell apoptosis and proliferation in keloid by transcriptional targeting of telomerase. These findings may suggest alternative strategies for managing patients with keloids in the near future.

\section{Acknowledgments}

This study was financially supported by Science Foundation of Heilongjian Province (No. QC2011C116) and Science Foundation of the First Affiliated Hospital of Harbin Medical University Province (No. 2015B010).

\section{Disclosure Statement}

None.

\section{References}

1 Corr DT, Hart DA: Biomechanics of Scar Tissue and Uninjured Skin. Adv Wound Care (New Rochelle) 2013;2:37-43.

2 Al-Attar A, Mess S, Thomassen JM, Kauffman CL, Davison SP: Keloid pathogenesis and treatment. Plast Reconstr Surg 2006;117:286-300.

3 Bock O, Schmid-Ott G, Malewski P, Mrowietz U: Quality of life of patients with keloid and hypertrophic scarring. Arch Dermatol Res 2006;297:433-438. 


\section{Cellular Physiology Cell Physiol Biochem 2016;39:2001-2013 \begin{tabular}{l|l|l|l|l}
\hline DOI: 10.1159/000447896 & $\begin{array}{l}\text { () 2016 The Author(s). Published by S. Karger AG, Basel } \\
\text { www.karger.com/cpb }\end{array}$
\end{tabular} \\ Yu et al.: Role of Wnt/ß-Catenin in Telomerase Regulation for Keloid}

4 Han J, Yu D, Xiao J, Shang Y, Hao L: Association of ADAM33 gene polymorphisms with keloid scars in a northeastern Chinese population. Cell Physiol Biochem 2014;34:981-987.

5 Orimolade EA, Olabanji JK, Oladele AO, Yusuf MB: Chronic osteomyelitis in the lower extremity predisposing to the unusual formation of keloids. Singapore Med J 2011;52:e190-193.

6 Sclafani AP, Gordon L, Chadha M, Romo T, 3rd: Prevention of earlobe keloid recurrence with postoperative corticosteroid injections versus radiation therapy: a randomized, prospective study and review of the literature. Dermatol Surg 1996;22:569-574.

7 Ma X, Chen J, Xu B, Long X, Qin H, Zhao RC, Wang X: Keloid-derived keratinocytes acquire a fibroblast-like appearance and an enhanced invasive capacity in a hypoxic microenvironment in vitro. Int J Mol Med 2015;35:1246-1256.

8 Yan L, Cao R, Wang L, Liu Y, Pan B, Yin Y, Lv X, Zhuang Q, Sun X, Xiao R: Epithelial-mesenchymal transition in keloid tissues and TGF-beta1-induced hair follicle outer root sheath keratinocytes. Wound Repair Regen 2015;23:601-610.

9 Li J, Bertram JF: Review: Endothelial-myofibroblast transition, a new player in diabetic renal fibrosis. Nephrology (Carlton) 2010;15:507-512.

10 Kose 0, Waseem A: Keloids and hypertrophic scars: are they two different sides of the same coin? Dermatol Surg 2008;34:336-346.

11 Ford CE, Henry C, Llamosas E, Djordjevic A, Hacker N: Wnt signalling in gynaecological cancers: A future target for personalised medicine? Gynecol Oncol 2015;140:345-351.

12 Pahnke A, Conant G, Huyer LD, Zhao Y, Feric N, Radisic M: The role of Wnt regulation in heart development, cardiac repair and disease: A tissue engineering perspective. Biochem Biophys Res Commun 2015;473:698-703.

13 Dong S, Wu C, Hu J, Wang Q Chen S, Wang Z, Xiong W: Wnt5a Promotes Cytokines Production and Cell Proliferation in Human Hepatic Stellate Cells Independent of Canonical Wnt Pathway. Clin Lab 2015;61:537-547.

14 Logan CY, Nusse R: The Wnt signaling pathway in development and disease. Annu Rev Cell Dev Biol 2004;20:781-810.

15 Angers S, Moon RT: Proximal events in Wnt signal transduction. Nat Rev Mol Cell Biol 2009;10:468-477.

16 Peifer M, Polakis P: Wnt signaling in oncogenesis and embryogenesis--a look outside the nucleus. Science 2000;287:1606-1609.

17 Struhl G: Evidence that Armadillo transduces wingless by mediating nuclear export or cytosolic activation of Pangolin. Cell 2004;116:481.

18 Bienz M, Clevers H: Armadillo/beta-catenin signals in the nucleus--proof beyond a reasonable doubt? Nat Cell Biol 2003;5:179-182.

19 Vincan E, Barker N: The upstream components of the Wnt signalling pathway in the dynamic EMT and MET associated with colorectal cancer progression. Clin Exp Metastasis 2008;25:657-663.

20 Wyatt HD, West SC, Beattie TL: InTERTpreting telomerase structure and function. Nucleic Acids Res 2010;38:5609-5622.

21 Blasco MA: The epigenetic regulation of mammalian telomeres. Nat Rev Genet 2007;8:299-309.

22 Kupiec M: Biology of telomeres: lessons from budding yeast. FEMS Microbiol Rev 2014;38:144-171.

23 Bertorelle R, Rampazzo E, Pucciarelli S, Nitti D, De Rossi A: Telomeres, telomerase and colorectal cancer. World J Gastroenterol 2014;20:1940-1950.

24 Hoffmeyer K, Raggioli A, Rudloff S, Anton R, Hierholzer A, Del Valle I, Hein K, Vogt R, Kemler R: Wnt/betacatenin signaling regulates telomerase in stem cells and cancer cells. Science 2012;336:1549-1554.

25 Chua AW, Ma D, Gan SU, Fu Z, Han HC, Song C, Sabapathy K, Phan TT: The role of R-spondin2 in keratinocyte proliferation and epidermal thickening in keloid scarring. J Invest Dermatol 2011;131:644-654.

26 Ou DL, Chen CL, Lin SB, Hsu CH, Lin LI: Chemokine receptor expression profiles in nasopharyngeal carcinoma and their association with metastasis and radiotherapy. J Pathol 2006;210:363-373.

27 Zhang Q, Yamaza T, Kelly AP, Shi S, Wang S, Brown J, Wang L, French SW, Le AD: Tumor-like stem cells derived from human keloid are governed by the inflammatory niche driven by IL-17/IL-6 axis. PLoS One 2009;4:e7798.

28 Qian X, Dong H, Hu X, Tian H, Guo L, Shen Q, Gao X, Yao W: Analysis of the interferences in quantitation of a site-specifically PEGylated exendin-4 analog by the Bradford method. Anal Biochem 2014;465:50-52. 


\section{Cellular Physiology Cell Physiol Biochem 2016;39:2001-2013 \begin{tabular}{ll|l} 
DOI: 10.1159/000447896 & $\begin{array}{l}\text { O 2016 The Author(s). Published by S. Karger AG, Basel } \\
\text { www.karger.com/cpb }\end{array}$
\end{tabular} \\ Yu et al.: Role of Wnt/ß-Catenin in Telomerase Regulation for Keloid}

29 Lee HW, Blasco MA, Gottlieb GJ, Horner JW, 2nd, Greider CW, DePinho RA: Essential role of mouse telomerase in highly proliferative organs. Nature 1998;392:569-574.

30 Rudolph KL, Chang S, Lee HW, Blasco M, Gottlieb GJ, Greider C, DePinho RA: Longevity, stress response, and cancer in aging telomerase-deficient mice. Cell 1999;96:701-712.

31 Valentijn AJ, Saretzki G, Tempest N, Critchley HO, Hapangama DK: Human endometrial epithelial telomerase is important for epithelial proliferation and glandular formation with potential implications in endometriosis. Hum Reprod 2015;30:2816-2828.

32 Jaitner S, Reiche JA, Schaffauer AJ, Hiendlmeyer E, Herbst H, Brabletz T, Kirchner T, Jung A: Human telomerase reverse transcriptase (hTERT) is a target gene of beta-catenin in human colorectal tumors. Cell Cycle 2012;11:3331-3338.

33 Serman L, Nikuseva Martic T, Serman A, Vranic S: Epigenetic alterations of the Wnt signaling pathway in cancer: a mini review. Bosn J Basic Med Sci 2014;14:191-194.

34 Arrazola MS, Silva-Alvarez C, Inestrosa NC: How the Wnt signaling pathway protects from neurodegeneration: the mitochondrial scenario. Front Cell Neurosci 2015;9:166.

35 Zhang Y, Toh L, Lau P, Wang X: Human telomerase reverse transcriptase (hTERT) is a novel target of the Wnt/beta-catenin pathway in human cancer. J Biol Chem 2012;287:32494-32511.

36 Choi J, Southworth LK, Sarin KY, Venteicher AS, Ma W, Chang W, Cheung P, Jun S, Artandi MK, Shah N, Kim SK, Artandi SE: TERT promotes epithelial proliferation through transcriptional control of a Myc- and Wntrelated developmental program. PLoS Genet 2008;4:e10.

37 Park JI, Venteicher AS, Hong JY, Choi J, Jun S, Shkreli M, Chang W, Meng Z, Cheung P, Ji H, McLaughlin M, Veenstra TD, Nusse R, McCrea PD, Artandi SE: Telomerase modulates Wnt signalling by association with target gene chromatin. Nature 2009;460:66-72.

38 Smith JC, Boone BE, Opalenik SR, Williams SM, Russell SB: Gene profiling of keloid fibroblasts shows altered expression in multiple fibrosis-associated pathways. J Invest Dermatol 2008;128:1298-1310.

39 Katoh M: WNT and FGF gene clusters (review). Int J Oncol 2002;21:1269-1273.

40 Igota S, Tosa M, Murakami M, Egawa S, Shimizu H, Hyakusoku H, Ghazizadeh M: Identification and characterization of Wnt signaling pathway in keloid pathogenesis. Int J Med Sci 2013;10:344-354.

41 Sato M: Upregulation of the Wnt/beta-catenin pathway induced by transforming growth factor-beta in hypertrophic scars and keloids. Acta Derm Venereol 2006;86:300-307.

42 Lee WJ, Park JH, Shin JU, Noh H, Lew DH, Yang WI, Yun CO, Lee KH, Lee JH: Endothelial-to-mesenchymal transition induced by Wnt 3a in keloid pathogenesis. Wound Repair Regen 2015;23:435-442.

43 Granick M, Kimura M, Kim S, Daniali L, Cao X, Herbig U, Aviv A: Telomere dynamics in keloids. Eplasty 2011;11:e15.

44 De Felice B, Wilson RR, Nacca M: Telomere shortening may be associated with human keloids. BMC Med Genet 2009;10:110.

45 Xiao Z, Hao L, Ren L, Teng W: Effect of wt-P53 protein on telomerase activity in keloid fibroblasts. Zhongguo Xiu Fu Chong Jian Wai Ke Za Zhi 2007;21:702-706. 